Article

\title{
Revisiting (Non-)Native Influence in VOT Production: Insights from Advanced L3 Spanish
}

\author{
Raquel Llama $^{1,2, *}$ and Walcir Cardoso ${ }^{3,4}$ (1) \\ 1 Department of Language Education, Stockholm University, Universitetsvägen 10E, \\ 10691 Stockholm, Sweden \\ 2 Language Acquisition Research Laboratory, Department of Modern Languages and Literatures, \\ University of Ottawa, 70 Laurier Avenue East, Ottawa, ON K1N 6N5, Canada \\ 3 Department of Education, Concordia University, 1455 de Maisonneuve Boulevard West, \\ Montreal, QC H3G 1M8, Canada; walcir.cardoso@concordia.ca \\ 4 Centre for the Study of Learning and Performance (CSLP), Concordia University, 1455 de Maisonneuve \\ Boulevard West, Montreal, QC H3G 1M8, Canada \\ * Correspondence: raquel.llama@isd.su.se
}

Received: 22 January 2018; Accepted: 24 July 2018; Published: 31 July 2018

\begin{abstract}
A growing body of research investigating cross-linguistic influence on the acquisition of a third phonological system suggests that first (L1) and second (L2) languages concur in influencing oral production in the target third language (L3). Yet, there are also claims of either a more noticeable effect of the L2 on the L3, or a prevailing influence from the L1. This study further explores whether the L1 and the L2 compete or converge on exerting influence on L3 pronunciation. To do so, we examine the production of voice onset time for voiceless stops by adult advanced learners of L3 Spanish divided into two groups (15 L1 English-L2 French, and 15 L1 French-L2 English speakers). Three monolingual control groups were also tested. Participants were recorded reading word lists that contained voiceless stops in stressed onset position. A Kruskal-Wallis test uncovered significant differences traceable to the L1-English speakers, which puts them at a slight disadvantage vis-à-vis their Francophone counterparts. These results favor claims of a more decisive role for the L1 in L3 pronunciation. We compare our results to findings from previous studies targeting intermediate learners, and find proficiency in the L3 may account for the observed differences.
\end{abstract}

Keywords: L1 influence; L2 influence; voice onset time; third language phonology

\section{Introduction}

Research on the acquisition of phonological systems beyond the second language (L2) is "a newly emerging dynamic area" (Cabrelli Amaro and Wrembel 2016, p. 395). However, within the recently established field of Third Language Acquisition (TLA), the acquisition of third language (L3) phonology has often been labeled as an understudied domain (Cabrelli Amarom 2012). While this has been the case in the last two to three decades, this trend in attention is finally reversing. Thanks to the upsurge experienced in recent years, studies devoted to L3 phonetics/phonology seem no longer to lag behind those dealing with L3 lexicon and L3 syntax.

In their state-of-the art overview of the subfield, Cabrelli Amaro and Wrembel (2016) list four general questions L3 phonology research has addressed so far, which revolve around the following issues: (i) the so-called bilingual advantage; (ii) the source and/or (iii) directionality of transfer, and (iv) the developmental path of acquisition of an L3 sound system. This study will add to the body of work devoted to the second issue, the source of transfer, which will also be referred to as cross-linguistic 
influence (CLI) throughout the paper. We will focus on forward transfer and lateral transfer as defined by Jarvis and Pavlenko (2008), that is, influence from the L1 to the L2/L3, and from the L2 to the L3.

When delving into CLI sources, it is not uncommon for studies dealing with L3 lexicon and syntax to test how L2 status and typological similarity compete and/or interact in determining which previously acquired language will become the main contributor of influence (for a discussion on the alleged competition between these two factors, see Sánchez (2011)). While typological similarity has been expected to boost positive L2-to-L3 transfer (Gut 2010; Mehlhorn 2007), it has not been reported as being a decisive factor in determining CLI in L3 pronunciation so far. The initial disregard towards the L2 as a source of phonological influence, or towards typology's role in promoting it, could be due to the fact that, generally, the native language seems to be regarded as the true hurdle to overcome in the acquisition of all sound systems beyond the L1. Drawing on observations from a seminal case study (Williams and Hammarberg 1998), Hammarberg (2009) reported that although his participant relied more on the L2 in the initial stages of L3 learning, L1 influence was more evident as L3 proficiency increased.

A predominant effect of the L1 on the L3 has been reported in earlier TLA investigations (e.g., Llisterri and Poch 1987; García Lecumberri and del Puerto 2003). Several recent studies, however, show that non-native languages can also considerably impact a developing L3 sound system (Kamiyama 2007; Llama et al. 2010; Tremblay 2007; Wrembel 2010—see also Bardel and Falk 2007, for similar claims in L3 syntax). An alternate finding increasingly reported in the TLA literature is the presence of combined transfer, understood as the interaction of two or more languages, which concur in influencing the target one, including language universals. More specifically, combined CLI has been defined as "a type of transfer that occurs when two or more languages interact with one another and concur in influencing the target language, or whenever one language influences another, and the already-influenced language in turn influences another language in the process of being acquired" (De Angelis 2007, p. 49). Examples of combined CLI in L3 pronunciation are provided by Benrabah (1991), who found that his Algerian Arabic-French bilinguals transferred L2 French vowels and L1 Arabic consonants to their L3 English. Similarly, Pyun (2005) found evidence of phonological knowledge in L3 Swedish traceable to phonological rules from L1 Korean (such as unreleased obstruents in syllable-final position), L2 English (such as r-coloring vowels when followed by /r/), the L3 itself (such as the deletion of / $\mathrm{r}$ / when followed by an alveolar consonant), and inter-rules, that is, rules developed by learners to act as bridges between the acquired languages and the language being acquired (such as /i/-epenthesis) ${ }^{1}$. Finally, Blank and Zimmer (2009) reported, for example, that the English vowel / / displayed overlap in the first and second formants (F1/F2) with its L2 equivalent, as well as overlap in F1 with its L1 equivalent. This, together with several similar instances, was interpreted as hybrid vowel production in the L3 English of an L1 Brazilian Portuguese/L2 French speaker.

In view of the mixed findings discussed so far, we designed a study with the main objective of further exploring the issue of native (L1) vs. non-native (L2) CLI on the acquisition of a third phonological system. To do so, we focused on the production of voice onset time (VOT, one of the most frequently studied properties in L3 phonology) by L3 learners at an advanced level of proficiency (an understudied group in TLA). It is generally believed that CLI patterns are more robust in early stages of acquisition. This does not mean, however, that CLI does not occur at more advanced stages (see De Angelis 2007, for a similar claim). Admittedly, it may be harder to identify CLI once a certain level of proficiency has been reached in the target language. Nonetheless, it seems reasonable to examine learners at all levels to broaden our understanding of proficiency effects on CLI. Moreover, recall Hammarberg (2009)

1 Pyun (2005) labels "inter-rules" those rules that shape the interlanguage of the learners but that do not exist as internal rules neither in the grammar of the source languages (namely Korean and English) nor in the grammar of the target language (Swedish). For an account of how these examples illustrate inter-rule creation/use and transfer of L1, L2 and L3 phonological rules, as well as additional examples of each category, please see (Pyun 2005, pp. 56-60)). 
claim of a shift of transfer source (from the L2 to the L1) in the pronunciation of his participant as a result of increased L3 proficiency. Choosing this property and this proficiency level allows, then, for an interesting comparison with results from a previous study by Llama et al. (2010), who targeted intermediate learners, and claimed a predominant influence from the L2. By conducting a partial replica of that study, we intend to see if a switch in source language will be observed. As in Llama et al. (2010), the L3 is Spanish and the background languages selected in this study are English (L1 or L2) and French (L2 or L1).

\section{Voice Onset Time in Second and Third Language Acquisition}

Third Language Acquisition researchers have given more attention to segmental properties (including phonetic knowledge such as VOT) than to suprasegmental ones, as tends to happen in Second Language Acquisition (SLA) research in general (Gut 2009). In fact, L3 phonology studies often turn to L2 work as a point of reference upon which to develop. Unsurprisingly, then, L3 research mirrors SLA tendencies in several ways, such as the imbalance between the number of studies focusing on production (more frequent) and those focusing on perception, or the bias in favor of segmental features, as just mentioned. Among the limited number of L3 phonetic/phonological issues that have been investigated so far, we find vowels (Blank and Zimmer 2009; Kamiyama 2007; Kopečková 2015; Lechner and Kohlberger 2014; Missaglia 2010; Sypiańska 2016), and a phonetic measure of phonemic voicing in stops: VOT (Liu 2016; Llama et al. 2010; Tremblay 2007; Wrembel 2014; Wunder 2011). Both vowels and VOT also happen to be the most frequently investigated aspects of L2 speech (see, for example, Cabrelli Amaro and Wrembel 2016; Hansen Edwards and Zampini 2008 for similar claims).

When (Lisker and Abramson 1964, p. 422) coined the term VOT, they defined it as "the time interval that marks the release [of the stop] and the onset of periodicity that reflects laryngeal vibration [for vowel production]". Voice onset time is the most commonly used phonetic measure of phonemic voicing in pre-vocalic stops. Of interest to this study, VOT production for voiceless stops is similar in Spanish and French, on the one hand, and different in English, on the other. When placed along a VOT continuum, Spanish and French voiceless stops are expected to fall within the 0 to $30 \mathrm{~ms}$ range associated with short lag (as per Cho and Ladefoged 1999 definition of voiceless unaspirated stops). In contrast, typical VOT values for their English counterparts are greater than $30 \mathrm{~ms}$ and often fall within a 60-100 ms range (Lisker and Abramson 1964), occupying the extreme end of the continuum labeled as long lag, as depicted in Figure 1.

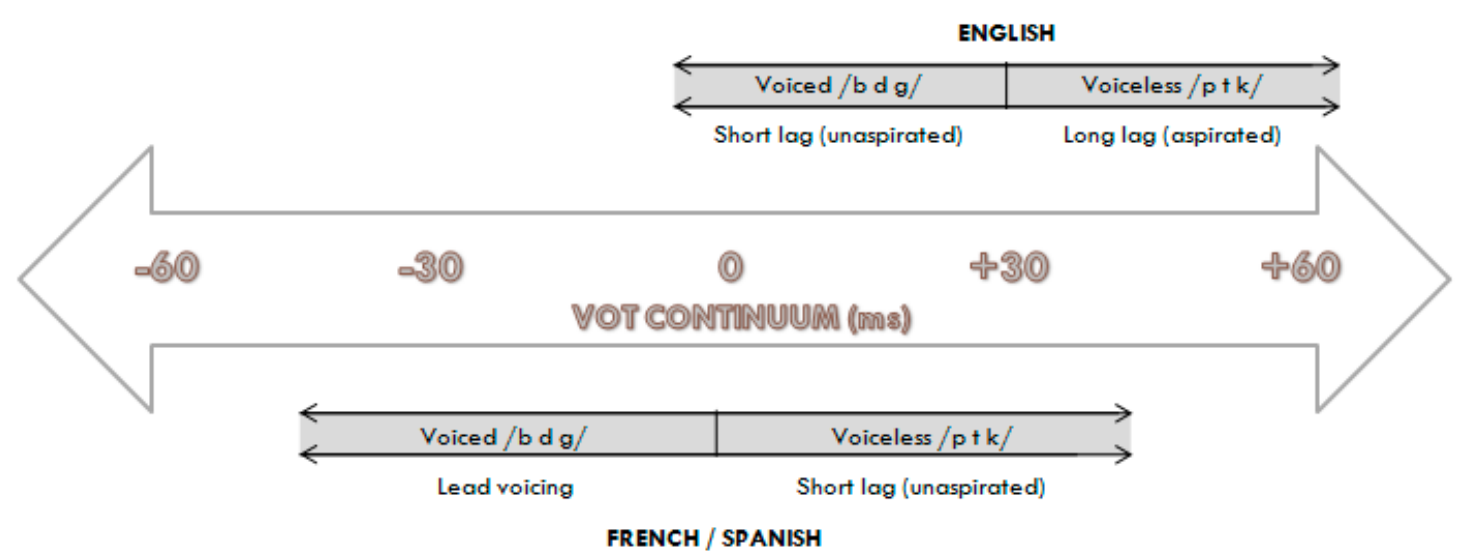

Figure 1. Schematic depiction of the relationship between English versus Spanish and French stops (adapted from Llama et al. 2010).

This divergence in lag patterns can result in another distinction in terms of presence (in long-lagged stops) vs. absence (in short-lagged stops) of aspiration, a feature typically described as 
an audible burst of air noticeable on the release of $/ \mathrm{p} \mathrm{t} \mathrm{k/} \mathrm{in} \mathrm{stressed} \mathrm{onset} \mathrm{position} \mathrm{in} \mathrm{English}$ (Avery and Ehrlich 1995). English speakers tend to produce Spanish (Lord 2005) and French (Fowler et al. 2008) voiceless stops with overly long VOTs (and thus with aspiration), which results in a noticeable accent (Lord 2005). Conversely, French and Spanish speakers tend to produce English voiceless stops with overly short VOTs, which may cause English speakers to perceive $/ \mathrm{p} /, / \mathrm{t} / / \mathrm{k} /$ as their corresponding voiced counterparts (due to the duration overlap between Spanish and French voiceless and English voiced stops, as shown in Figure 1). These issues have made VOT an interesting candidate for investigation in studies involving speakers of English and a Romance language either from an acquisition (see Section 2.1) or, less frequently, from a pedagogical standpoint (Kissling 2013; Lord 2005; Suarez 2008; among others).

\subsection{L2 Acquisition of Voice Onset Time}

Studies on the acquisition of L2 VOT patterns are not in short supply, and a comprehensive review would require considerable space. What follows is a brief account of a selection of investigations that can offer the reader insight into what our Francophone and Anglophone participants' VOT production may have resembled in their background languages before they started learning Spanish as an L3.

Countless are the investigations into the phonological acquisition of bilinguals who speak language pairs that differ in VOT patterns. Such studies' focus has often been placed on comparing the participants' production and/or perception of VOT to determine whether the different types of speakers (simultaneous vs. sequential bilinguals, for example) develop two separate systems or employ a shared range of values for both languages. Transfer of L1 VOT patterns to the L2 seems to be a common scenario with learners at lower levels of proficiency (Flege 1987). However, many studies have revealed that more proficient L2 speakers tend to depart from L1 values and approach (or reach) native-like production in their L2, with varying degrees of success. Some speakers produce L2 voiceless stops with VOT values that are intermediate between those of monolinguals and their L2 (Caramazza et al. 1973; Flege and Eefting 1987; Flege 1991; Gurski 2006; Laeufer 1996). Yet others exhibit rather monolingual-like VOT patterns for some stops but not necessarily for all. For example, when investigating the production of voiced and voiceless stops by adult bilingual and monolingual speakers of Canadian English (CEn) and Canadian French (CFr), Sundara et al. (2006) and MacLeod and Stoel-Gammon (2009) observed their participants maintained monolingual-like contrasts for all French stops and some of the English voiceless stops tested, but not for English $/ \mathrm{b} d /$. These findings bring to light two ideas pertinent to our work. On the one hand, and despite reports that attaining native-like VOT is hardly ever possible (Caramazza et al. 1973; Díaz-Campos 2004; Fellbaum 1996), they provide proof of such an achievement for voiceless stops in L2 CEn and CFr. On the other, they instigate the hypothesis that mastering VOT can be easier in French voiced stops than in English ones.

Given that our participants are Francophones and Anglophones who have attained a high level of proficiency in their L2 (English or French), it could be assumed that they have either approximated or achieved native-like VOT durations in their L2, which could have in turn led to a modification of their L1 values, as has been shown to happen in previous L3/L2 studies (Sypiańska 2013; Waniek-Klimczak 2011).

\subsection{L3 Acquisition of Voice Onset Time}

The production of VOT has also received a good deal of attention in the L3 literature (see, for example, Aoki and Nishihara 2013; Bandeira and Zimmer 2012; Beckmann 2012; Dittmers et al. 2018; Gabriel et al. 2016; Liu 2016; Llama et al. 2010; Llama and López-Morelos 2016; Tremblay 2007; Wrembel 2011, 2014, 2015; Wunder 2011). Among the reasons that may have contributed to spur interest on VOT among SLA and TLA researchers are repeated suggestions that it is correlated with degree of foreign accent (Major 2001; Riney and Takagi 1999). 
L3 VOT studies feature a variety of data collection methods, bilingual profiles, and language combinations, and not all are equally pertinent to the current study. As indicated earlier, the most relevant is Llama et al. (2010), who investigated which of two factors, L2 status or typological similarity, was most likely to predict the source language for CLI during L3 VOT production. To answer this question, they tested two groups of intermediate learners of L3 Spanish, whose previously learnt languages were L1 English/L2 French or L1 French/L2 English. Participants from both groups seemed to produce similar VOT means in their L2s and L3, which was interpreted as an L2-to-L3 transfer pattern. It was observed, however, that they appeared to have retained some L1 phonetic traces in their L2, which prevented the authors from providing an unambiguous answer to their research question. Considering that the values achieved in the L2 were already influenced by the L1, and that this already-influenced L2 had an impact on L3 performance, the authors suggested combined CLI as a second explanation for their findings. In this partial replica of that work, we address one of the main limitations of Llama et al.: the lack of L1 data from experimental groups.

At this point, it is pertinent to discuss the overall similarities and differences between Llama et al. (2010) study and the current one. They both employ a mirror design for the two experimental groups, that is, the second group speaks the same background languages as the first group but in reverse order. However, two subtle, yet potentially decisive, differences regarding participants are: (i) their level of L3 proficiency, which is higher (advanced) in our study; and (ii) their place of residence (a French-dominant city in their case vs. an English-dominant city in ours). In terms of the instruments used, both studies use read-aloud tasks featuring word lists. However, our instruments have been slightly modified, as will be described in the Methodology section.

Similar to Llama et al. (2010), the study by Tremblay (2007) targeted the same background languages (English and French), while the study by Wunder (2011) focused on Spanish as the L3. Tremblay investigated VOT production by L1 English-L2 French bilinguals who were beginner learners of L3 Japanese. They produced strikingly similar patterns in their L2 French and L3 Japanese, and Tremblay put forward two possible explanations for this result. The first one was a predominant L2 effect in the production of L3 Japanese voiceless stops, which agrees with previous reports that L2 status prevails at the early stages of L3 phonological acquisition. The second explanation was a purported acquisition of Japanese values due to the participants' enhanced abilities as experienced language learners. In her conclusion, Tremblay opts for the first possibility, with a caveat: the L2 seemed to be already influenced by the L1, which could help one argue in favor of combined CLI being at play.

Wunder (2011) set up a study to shed light on the issue of whether it was L2 status rather than combined CLI that explained the L3 values obtained by previous studies such as Llama et al. (2010) and Tremblay (2007). She recruited eight L1-German /L2-British English speakers, who were either high beginner or advanced learners of L3 Spanish. Instead of reading lists, the author selected a short text for a read-on-your-own task, which yielded rather mixed results. With L3 VOT means that fell in between those of L1 German and L2 English, Wunder explained that "some CLI from the L2 existed, but a prominent L1 effect was also detected" (p. 122). The limited number of participants prevented her from creating two separate groups according to L3 proficiency. Everything considered, Wunder interpreted her results as contradicting rather than corroborating findings of a prevailing L2 status effect, and as pointing instead to combined CLI as an explanation for the findings observed.

The available literature on L3 VOT shows that the acquisition of VOT patterns in an L3 is not fully understood. Overall, we could classify reported results in three main categories: (i) studies that claim a predominant L2 effect (Llama et al. 2010; Tremblay 2007); (ii) studies that report combined CLI (Wrembel 2011, 2015; Wunder 2011); (iii) studies that report a predominant L1 effect (Bandeira and Zimmer 2012). Of notice, several authors report mixed results, which may be explained in more than 
one way: L2 status or combined CLI (Llama et al. 2010), combined CLI or L1 effect (Wunder 2011)2. Against this backdrop, the research question addressed in this study is which (or whether) one of the previously acquired language exerts the strongest influence on L3 pronunciation at a high level of proficiency.

In light of the overview we have presented, we predict that the outcome will be triggered by combined CLI with an underlying L1 effect (Hammarberg 2009; Wunder 2011). More precisely, we believe that having learnt an L2 will have a somewhat negative effect (i.e., increase in VOT values relative to the L1) for Group TF (Trilingual Francophones), and a somewhat positive effect (i.e., reduction in VOT values relative to the L1) for Group TA (Trilingual Anglophones) on L3 production. However, we expect the L1 to ultimately affect achievement in the L2. This underlying L1 effect will still leave Anglophones at a slight disadvantage relative to Francophones, who will better approximate Spanish values. Nonetheless, combined CLI can also manifest itself in the form of hybrid values, as reported in several VOT bilingual studies (Flege 1987; Flege and Eefting 1987; Gurski 2006). This would imply the production of intermediate values (between those attributable to English and French) in the L1, L2 and L3, which would indicate that our participants have some sort of a merged VOT system. Out of these two combined CLI scenarios, the latter seems less likely, given that highly proficient, early CEn-CFr bilinguals have been shown to produce distinct VOT for voiceless stops in English and French (MacLeod and Stoel-Gammon 2009).

We acknowledge other outcomes are plausible. Among them, a scenario that should not be ruled out when learners have reached a high level of proficiency is the acquisition of the target Spanish VOT patterns. Admittedly, this outcome cannot be clearly teased apart from L1-influenced production in the case of Francophone speakers (provided L1 French values have been maintained), and L2-influenced production in the case of Anglophone speakers (provided target values have been achieved in the L2 French).

\section{Methodology}

\subsection{Participants}

Two experimental and three control groups were recruited. The first experimental group, henceforth Group TA (trilingual Anglophones), consisted of 15 L1 CEn speakers with an advanced knowledge of CFr, their L2. The second, henceforth Group TF (trilingual Francophones), was made up of $15 \mathrm{~L} 1 \mathrm{CFr}$ speakers with an advanced knowledge of CEn, their L2. All of them were high intermediate to advanced learners of Spanish, their L3, and were recruited either at a university, or through the organizers of two Spanish conversation clubs in Ottawa, a predominantly English-speaking Canadian city. Consequently, they did not form as homogeneous a group as desired, especially in terms of age. Please note that the mean ages were $30.13(\mathrm{SD}=17.14)$ for Group TA, and $37.87(\mathrm{SD}=15.81)$ for Group TF. All recruited candidates met three main criteria: (i) they were not simultaneous bilinguals (i.e., they did not consider English and French as two L1s); (ii) they were more proficient in their L2 than in their L3; ${ }^{3}$ and (iii) they had no or very limited knowledge of any languages besides English,

2 It is worth noting that the studies cited in this paragraph have concentrated on learners at the beginner and/or intermediate levels of L3 proficiency, with varying levels of L2 proficiency. Within this context, it is complicated to estimate the role proficiency in the non-native languages may play in accounting for the different outcomes. In fact, most L3 researchers control for proficiency but hardly ever make this variable the focus of investigation. Future studies should target L2 and L3 proficiency, so we can gain insight into this factor's impact on CLI in TLA.

3 As pinpointed by several authors (Hammarberg 2010; García-Mayo 2012; among others), the terms first, and specially, second and third language are used ambiguously and variably in the literature. In fact, a multilinguals' languages can be labeled either in a chronological sense or according to other characteristics. For a comprehensive discussion on this terminological issue, the reader is referred to Hammarberg (2010). Regarding the purposes of this study, L2 is to be understood strictly as the second language for our participants not only because of the order of acquisition but also in terms of proficiency, i.e., it is the language learnt after the L1 and the level of proficiency in that language is lower than in the L1, but higher than in the L3. 
French and Spanish. The selection of location for data collection was mainly based on our ability to recruit participants who met these three criteria.

In our increasingly multilingual world, true monolingual participants who have never studied and never use an L2 are rare to come by. As a result, our three control groups consist mostly of functional monolinguals, that is, of speakers who live in an L1-dominant environment, interact in their L1 as part of their daily routine, and are seldom exposed to other languages. They have had some formal instruction in their L2, one of the two official languages of Canada, but hardly ever use it. Crucially, they have never lived in a setting where their L2 is the community language. The 15 participants in the Spanish control group, henceforth Group MS (Spanish monolinguals), were recruited in a small town in a monolingual region of Northern Spain and are therefore native speakers of Castilian Spanish (CSp). Their ages ranged between 19 and 43 years (mean $=27.87, \mathrm{SD}=7.44$ ).

Participants in the monolingual Anglophone group, henceforth Group MA $(n=8)$, were recruited in Ottawa, where they currently live, although some of them were raised in other English-speaking Canadian cities. Their mean age was $48.3(\mathrm{SD}=12.15)$. Lastly, the 15 participants in the monolingual Francophone group, henceforth Group MF, were recruited in three small towns in the province of Quebec. Their mean age was $36.93(\mathrm{SD}=17.85)$. For an overview of these groups' linguistic profiles, see Table 1. All participants in the control and experimental groups signed a consent form in their L1 and received a monetary compensation.

Table 1. Control and experimental groups' linguistic profiles.

\begin{tabular}{cccccc}
\hline & Group & $\boldsymbol{n}$ & L1 & L2 & L3 \\
\hline \multirow{2}{*}{ Experimental } & TA & 15 & CEn & CFr (Ad) & Sp (Ad/Hi) \\
& TF & 15 & CFr & CEn (Ad) & Sp (Ad/Hi) \\
\hline \multirow{4}{*}{ Control } & MA & 8 & CEn & CFr (Be) & - \\
& MF & 15 & CFr & CEn (Be) & - \\
& MS & 15 & CSp & En (Be) & - \\
\hline
\end{tabular}

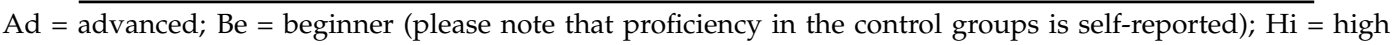
intermediate (according to their proficiency test scores, three participants from Group Trilingual Francophones (TF) and four participants from Group Trilingual Anglophones (TA) were high intermediate rather than advanced learners); MA: Monolingual Canadian English Speaker; MF: Monolingual Canadian French Speaker; MS: Monolingual Castilian Spanish Speaker; CEn: Canadian English; CFr: Canadian French; CSp: Castilian Spanish; Sp: Spanish (any variety of Spanish).

\subsection{Instruments}

The instruments used for this study were a Language Background Questionnaire (LBQ), three proficiency tests, and three reading aloud tasks consisting of word lists. The LBQ was taken, with minor modifications, from the Language Acquisition Research Laboratory (LAR Lab) at the University of Ottawa, and has been used by a series of its members in several studies. This questionnaire was key in ensuring the informants' suitability for participation, since they were asked to state the number of languages they spoke, how often they used them, and the order in which they were acquired. The participants' L2 and L3 proficiency was assessed via a set of standardized grammar tests readily available on-line: the placement tests used by the University of Oxford Language Centre.

Word lists are commonly used for gathering VOT measures in a controlled way, both in L2 (Flege 1991; Yavaş and Wildermuth 2006) and in L3 studies (Tremblay 2007; Wrembel 2014). The lists, which can be found in Appendix A, are a shorter version of those employed by Llama et al. (2010), with 30 items (of which we analyze 18) per language. Shortening the lists allowed for the exclusion of certain items such as cognates like taxi or taco, which could trigger the pronunciation of the word in a non-intended language. In addition, some items were not retained but rather replaced by new ones based on syllable complexity: syllabically complex words such as cor-to (CVC) were substituted by simpler ones such as $\underline{c o-d o}(\mathrm{CV})$. The lists consisted of real words with the following restrictions: 
they (i) were either disyllabic or monosyllabic, ${ }^{4}$ (ii) contained a "voiceless stop + vowel" sequence (a typical CV syllable structure), and (iii) the voiceless stop occurred in stressed, word-initial onset position (e.g., / pa.to/ 'duck'). The stimuli (six /p/-, six /t/-, and six /k/- initial words) were presented on a computer screen, one at a time. A pause was created in between stimuli to ensure they were produced in isolation.

\subsection{Procedure}

The data collection took place at a quiet environment either at the LAR Lab, or at a place convenient for the participant. Participants in the experimental groups were tested over the course of two one-hour sessions. The first session was always held in L3 Spanish, except for the consent form and the LBQ, which participants filled out in their L1. The first half of the second session was devoted to the tasks in the L2, and the second half to the L1 tasks. The readings of the word lists were audio recorded using a Zoom H4n Handy Digital Recorder (Zoom North America, Hauppauge, NY, USA) and saved as 16-bit mono files at $44.1 \mathrm{kHz}$ sampling.

\subsection{Data Analysis}

The program PRAAT 5.3.78 (Boersma and Weenink 2014) was used to perform the acoustic analysis of a total of 2298 tokens. As is standard in the literature, VOT measurements are reported in milliseconds (ms); these values correspond to the interval between the stop release and the beginning of regular vocal fold vibration for the production of the following vowel. For details about the computation of VOT values in PRAAT, see the discussion around Figure 1 and Llama et al. (2010).

We analyzed combinations of /p t k/ + low and mid vowels. Since / $/$ tends to affricate in Canadian French when followed by a high vowel, consequently lengthening the VOT, "voiceless stop + high vowel" sequences were included in the reading lists but excluded from analysis for all groups of participants and all languages.

\section{Results}

We report mean VOT values as produced by control (monolingual) and experimental (trilingual) participants. We performed Kruskal-Wallis tests to reveal any significant differences regarding VOT production across the control and experimental groups ${ }^{5}$ as well as within the experimental groups. When significant differences were found, post hoc comparisons ensued, namely Mann-Whitney-Wilcoxon (for paired comparisons) and Dunn's (for two-to-one comparisons) tests, as required. The alpha value was set at 0.05 .

\subsection{Control Groups}

The Spanish word list yielded a total of 270 tokens for analysis from Group MS. Their means per stop are $/ \mathrm{p} /=14.82 \mathrm{~ms}, / \mathrm{t} /=18.18 \mathrm{~ms}, / \mathrm{k} /=30.58 \mathrm{~ms}$. The 270 tokens obtained from Group MF yielded the following means per target stop: $18.33 \mathrm{~ms}$ for /p/, $23.07 \mathrm{~ms}$ for /t/, and $45.82 \mathrm{~ms}$ for $/ \mathrm{k} /$. Lastly, after discarding two tokens (due to mispronunciation), the 142 tokens analyzed from Group MA resulted in the following means: $76.9 \mathrm{~ms}$ for $/ \mathrm{p} /, 86.65 \mathrm{~ms}$ for $/ \mathrm{t} /$, and $90.19 \mathrm{~ms}$ for $/ \mathrm{k} /$.

4 In French, word-level stress falls on the rightmost syllable. To ensure the production of voiceless stops in stressed, onset position, words in the French list are monosyllabic.

5 An anonymous reviewer questioned the usefulness of comparing our findings to native speaker means when determining the L1/L2 influence on the L3. We believe that reporting these comparisons allows for the presentation of our findings in a more nuanced way, with a more comprehensive analysis of our participants' behavior in all their known languages. Moreover, it is common practice in similar L3 studies to compare VOT means either to L1 control groups (e.g., Aoki and Nishihara 2013; Beckmann 2012; Gabriel et al. 2016) or to L1 reference values from the literature (e.g., Bandeira and Zimmer 2012; Dittmers et al. 2018; Wrembel 2011). 
All means from the three control groups, portrayed in Figure 2, will be used as a baseline to determine the extent to which the L2 and the L3 values have been acquired, and the L1 values maintained.

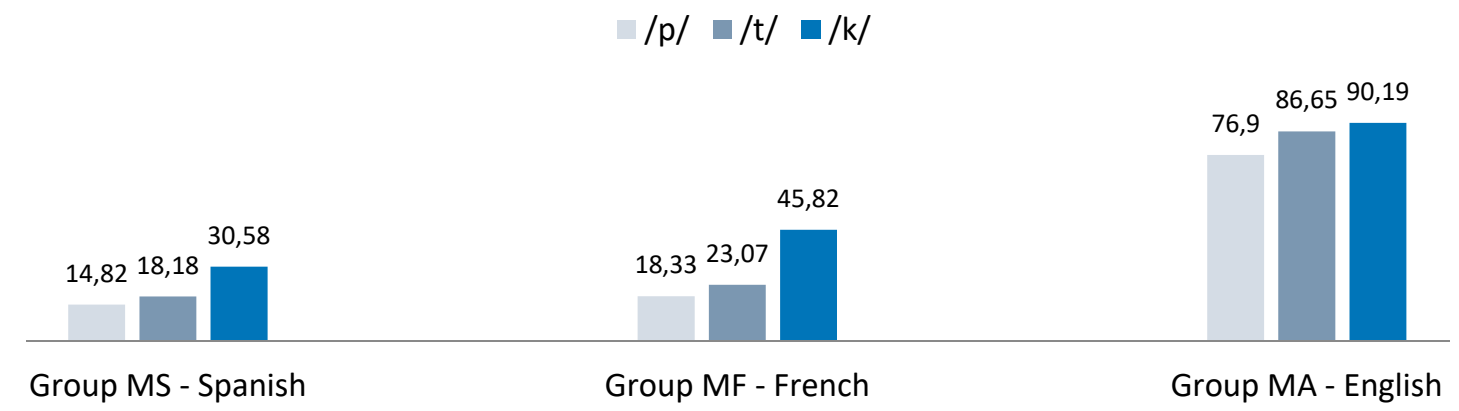

Figure 2. Mean Voice Onset Time (VOT) (ms) in the voiceless stops of monolingual speakers of Castilian Spanish (MS), Canadian French (MF), and Canadian English (MA).

\subsection{Experimental Groups}

For our trilingual data, we report the results organized in terms of language. We focus first on the two background languages, and then turn to the L3.

\subsubsection{French as an L1 and an L2}

We analyzed a total of 270 French tokens from Group TF, and 267 from Group TA. L1 French means are $27.8 \mathrm{~ms}$ for $/ \mathrm{p} /, 39.11 \mathrm{~ms}$ for $/ \mathrm{t} /$, and $54.6 \mathrm{~ms}$ for $/ \mathrm{k} /$, as shown in Figure 3. These are higher than the means reported from the monolinguals, although lower than the means from Group TA's L2 French: $/ \mathrm{p} /=46.48 \mathrm{~ms}, / \mathrm{t} /=53.43 \mathrm{~ms}, / \mathrm{k} /=61.7 \mathrm{~ms}$, portrayed in Figure 4. The Kruskal-Wallis test used to compare the experimental and control groups was significant for $/ \mathrm{p} /, \chi^{2}(2,45)=20.949$, $p=0.00002 ; / \mathrm{t} /, \chi^{2}(2,45)=25.366, p=0.000003 ;$ and $/ \mathrm{k} /, \chi^{2}(2,45)=8.6779, p=0.013$.

$$
\square / \mathrm{p} / \square / \mathrm{t} / \square / \mathrm{k} /
$$

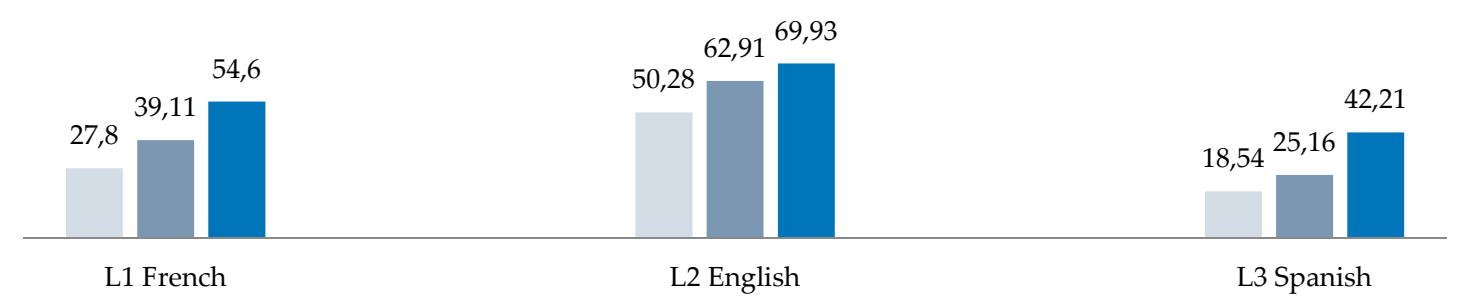

Figure 3. Mean VOT (ms) in the voiceless stops of Group TF in L1 French, L2 English and L3 Spanish.

$$
\square / \mathrm{p} / \square / \mathrm{t} / \square^{\prime} / \mathrm{k} /
$$

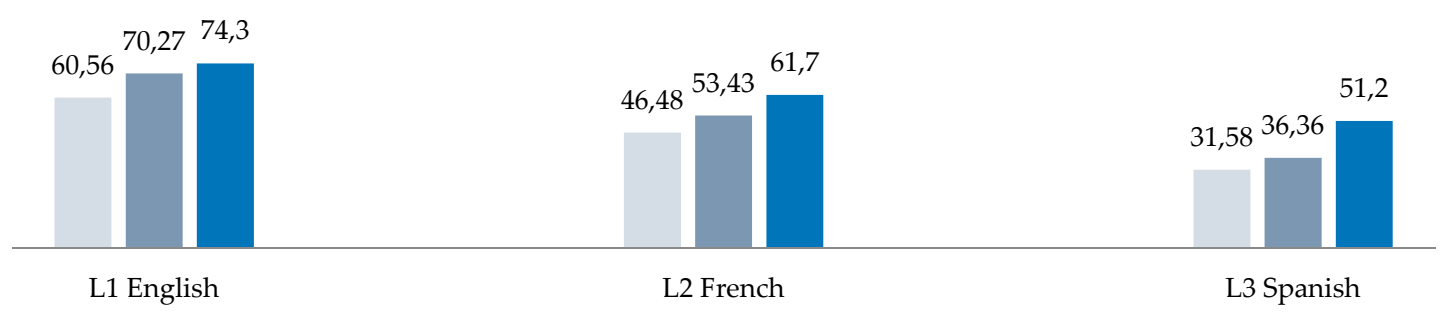

Figure 4. Mean VOT (ms) in the voiceless stops of Group TA in L1 English, L2 French and L3 Spanish. 
To trace the significant differences to one or both experimental groups, Mann-Whitney-Wilcoxon tests followed. These tests showed that all groups behaved significantly differently from each other in the case of $/ \mathrm{p} /$ and $/ \mathrm{t} /$, but the experimental groups behaved alike regarding $/ \mathrm{k} /$ and, together, they differed from the control group. This indicates that our trilingual Anglophones have not fully acquired L2 French values, whereas trilingual Francophones have departed from the monolingual French norm, that is, produce voiceless stops with a longer lag than expected for this language.

\subsubsection{English as an L1 and L2}

The English list yielded 268 (plus two mispronounced) tokens from Group TF and 270 from Group TA. Group TA's L1 English means, represented in Figure 4, are: $/ \mathrm{p} /=60.56 \mathrm{~ms}, / \mathrm{t} /=70.27$ $\mathrm{ms}$, and $/ \mathrm{k} /=74.3 \mathrm{~ms}$. With a drop of no less than $15 \mathrm{~ms}$ per stop if compared to the Anglophone control group, these trilingual Anglophones also seem to have departed from English monolingual norms. Group TF's L2 English means, displayed in Figure 3, are: /p/ $=50.28 \mathrm{~ms}, / \mathrm{t} /=62.91 \mathrm{~ms}, / \mathrm{k} /$ $=69.93 \mathrm{~ms}$. Once again, the Kruskal-Wallis test yielded significant differences for all three stops, as follows: $/ \mathrm{p} /, \chi^{2}(2,38)=12.468, p=0.001 ; / \mathrm{t} /, \chi^{2}(2,38)=11.79, p=0.002 ;$ and $/ \mathrm{k} /, \chi^{2}(2,38)=11.292$, $p=0.003$. To determine which group(s) this significant difference could be attributed to, we employed Mann-Whitney tests, which indicated no significant differences between the experimental groups.

This suggests that, unlike in the case of French, both experimental groups behave alike in English, and together are significantly different from the relevant control group of monolingual speakers. While trilingual Anglophones better approximate English norms, overall there is a smaller (and non-significant) difference between experimental groups in this language than there was for French. Crucially, and despite the significant difference from monolinguals, both experimental groups produced means that could be placed on the long-lag side of the VOT continuum depicted in Figure 1, and consistent with English-like production.

\subsubsection{Spanish as an L3}

In L3 Spanish, we gathered 270 tokens from each group. Spanish L3 means are $18.54 \mathrm{~ms}$ for /p/, $25.16 \mathrm{~ms}$ for /t/, and $42.21 \mathrm{~ms}$ for / $/ \mathrm{k}$ for Group TF, and $31.58 \mathrm{~ms}$ for /p/, $36.36 \mathrm{~ms}$ for /t/, and $51.2 \mathrm{~ms}$ for $/ \mathrm{k} /$ for Group TA. Trilingual Francophones approximate Spanish monolingual values, especially in the case of bilabials. In fact, although the Kruskal-Wallis determined there was a significant difference regarding $/ \mathrm{p} /\left(\chi^{2}(2,45)=15.266, p=0.004\right)$, the difference was ultimately traceable to Group TA (when compared in pairs using Mann-Whitney-Wilcoxon tests). Therefore, regarding this stop, Francophones pattern with Spanish monolinguals, as indicated by the grey cells ${ }^{6}$ in Table 2.

A significant difference among all groups was obtained once again, this time regarding Spanish $/ \mathrm{t} /$ $\left(\chi^{2}(2,45)=17.896, p=0.0001\right)$. Although they have achieved a further reduction of means if compared to their L2, trilingual Anglophones deviate from monolingual Spanish norms more than trilingual Francophones. Nonetheless, the post hoc tests revealed that all three groups behaved significantly differently from each other (see summary in Table 2). Trilingual Francophones are closer to, yet still different from, Spanish monolinguals.

A third, interesting scenario emerges regarding $/ \mathrm{k} /$. Whereas a Kruskal-Wallis test indicated a significant difference across groups once more $\left(\chi^{2}(2,45)=19.802, p=0.000005\right)$, the Mann-Whitney-Wilcoxon and Dunn's tests that ensued revealed that the experimental groups were not significantly different among themselves, and together they were significantly different to the control group (see summary of results in Table 2).

6 Please note that grey-shaded cells represent language pairs that show some overlap, as per the lack of significant differences yielded by the post hoc tests. White cells, on the other hand, display values that have been found to differ significantly from the means in other cells within the same column. 
Table 2. Intergroup comparisons for all three voiceless stops in Spanish.

\begin{tabular}{cccc}
\hline & $/ \mathrm{p} /$ & $/ \mathbf{t} /$ & $/ \mathbf{k} /$ \\
\cline { 2 - 4 } & Mean (SD) & Mean (SD) & Mean (SD) \\
\hline Group MS & $14.82(3.85)$ & $18.18(4.85)^{*}$ & $30.58(4.58)^{*}$ \\
Group TF & $18.54(5.42)$ & $25.16(7.42)^{*}$ & $42.21(9.77)$ \\
Group TA & $31.58(15.63)^{*}$ & $36.36(15.52)^{*}$ & $51.2(14.8)$ \\
\hline
\end{tabular}

*: Asterisks indicate statistical significance. Grey shading: Grey-shaded cells contain language pairs for which no significant difference was found (see footnote 6).

In sum, regarding L3 Spanish, a complex picture of acquisition emerges from these findings, which reveal different production patterns for each stop. To better answer our research question, however, it is necessary to examine the overall patterns observed, rather than concentrate only in Spanish. For ease of comparison across the three languages between the two experimental groups, we provide a summary of the results obtained in Table 3.

We had hypothesized that a combined influence, with an underlying L1 effect would be the answer to the question of which (or whether) one of the background languages exerts the strongest influence on L3 pronunciation at a high level of proficiency. With L3 Spanish VOT means lower than those in any of the previously learnt languages, our results point to the acquisition of Spanish values to some extent, which was one of the outcomes that we anticipated. In our opinion, however, the obtained means also reveal the retention of L1 traits in the two non-native languages, as will be argued in the Discussion section.

Table 3. Summary of VOT means in all languages from both experimental groups.

\begin{tabular}{|c|c|c|c|c|c|c|c|}
\hline & \multicolumn{3}{|c|}{ Group TA } & \multicolumn{4}{|c|}{ Group TF } \\
\hline & $/ \mathrm{p} /$ & $/ \mathrm{t} /$ & $/ \mathbf{k} /$ & & $/ \mathrm{p} /$ & $/ \mathrm{t} /$ & $/ \mathbf{k} /$ \\
\hline \multicolumn{5}{|c|}{ Mean (SD) } & \multicolumn{3}{|c|}{ Mean (SD) } \\
\hline EN (L1) & 60.56 (16.96) & 70.27 (14.69) & 74.3 (12.49) & EN (L2) & $50.28(12.79)$ & $62.91(13.19)$ & $69.93(11.07)$ \\
\hline FR (L2) & $46.48(21.58)$ & $53.43(19.42)$ & 61.7 (17.92) & FR (L1) & $27.8(8.35)$ & $39.11(9.22)$ & 54.6 (11.93) \\
\hline SP (L3) & 31.58 (15.62) & $36.36(15.52)$ & $51.2(14.81)$ & SP (L3) & $18.54(5.42)$ & $25.16(7.42)$ & 42.21 (9.77) \\
\hline
\end{tabular}

\subsubsection{Comparison of VOT Means Across the L1, the L2, and the L3}

We also compared each group's three languages. These intragroup comparisons could add or subtract support to claims that bi/multilinguals sometimes develop merged VOT systems, and help to further explore the interactions between the three languages spoken by our participants. The details of such comparisons are presented in Table 4 . Note that the U scores presented are the output of a Mann-Whitney $U$ test used to assess whether two independent groups are significantly different from each other; consequently, these scores help us assess, indirectly, the difference, or lack thereof, between the means/medians of the two groups being compared. 
Table 4. Cross-language comparison of VOT means within each experimental group.

\begin{tabular}{|c|c|c|c|c|c|c|c|}
\hline & \multicolumn{3}{|c|}{ Group TA } & & \multicolumn{3}{|c|}{ Group TF } \\
\hline & Language Pairing & $\mathbf{U}$ & $p$ & & Language Pairing & $\mathbf{U}$ & $p$ \\
\hline \multirow{3}{*}{$/ \mathrm{p} /$} & L1 vs. L2 & 69 & 0.071 & & L1 vs. L2 & 19.50 & $\leq 0.001^{*}$ \\
\hline & L2 vs. L3 & 66 & 0.054 & $/ \mathrm{p} /$ & L2 vs. L3 & 6.00 & $\leq 0.001$ * \\
\hline & L1 vs. L3 & 22.00 & $\leq \underset{*}{\leq 0.001}$ & & L1 vs. L3 & 34.00 & $\leq 0.001$ * \\
\hline \multirow{3}{*}{$/ \mathbf{t} /$} & L1 vs. L2 & 52.50 & $0.013 *$ & & L1 vs. L2 & 16.00 & $\leq 0.001 *$ \\
\hline & L2 vs. L3 & 57.50 & $0.023 *$ & $/ \mathrm{t} /$ & L2 vs. L3 & 0.00 & $\leq 0.001$ * \\
\hline & L1 vs. L3 & 15 & $\underset{*}{\leq 0.001}$ & & L1 vs. L3 & 27.00 & $\leq 0.001$ * \\
\hline \multirow{3}{*}{$/ \mathbf{k} /$} & L1 vs. L2 & 73 & 0.101 & & L1 vs. L2 & 34.50 & $\leq 0.001$ * \\
\hline & L2 vs. L3 & 66 & 0.054 & $/ \mathbf{k} /$ & L2 vs. L3 & 2.00 & $\leq 0.001 *$ \\
\hline & L1 vs. L3 & 30.00 & $0.001 *$ & & L1 vs. L3 & 38 & $0.002 *$ \\
\hline
\end{tabular}

*: Asterisks indicate statistical significance. Grey shading: Grey-shaded cells contain language pairs for which no significant difference was found (see footnote 6).

The Mann-Whitney tests performed for Group TA revealed that Anglophones' /p/ and / $\mathrm{k} /$ were not significantly different in the L1 and L2, and in the L2 and L3. An overlap in these two language pairs could cautiously be interpreted as potential forward (L1-L2) and lateral (L2-L3) interaction, while in the L1 and the L3 they remain as distinct categories. In contrast, the production of voiceless stops across Group TF's three languages was found to be significantly different in all cases for all language pairings, which could possibly be interpreted as proof of separate rather than merged (hybrid) VOT systems in the speech of the trilingual Francophones. Curiously, none of the French and Spanish voiceless stops by this group patterned together, although from a typological point of view they should. Interestingly, their VOT productions in L1 French are higher and less-target-like than their productions in L3 Spanish. This suggests that having learnt English seems to have had a stronger effect on the L1 than on the L3.

\section{Discussion}

This study set out to examine which previously acquired language exerts the strongest influence on L3 pronunciation at a high level of proficiency. Our findings have revealed a complex picture of L3 acquisition and interplay across the three languages. As indicated earlier, the current study was a partial replication of Llama et al. (2010), in which we employed similar instruments and tested participants with relatively comparable profiles, except for level of proficiency and the place of residence, so that we could examine the effects of higher proficiency levels on phonological CLI. The discussion of our findings, presented below, includes: (i) a comparison of the experimental group's L1 and L2 production to the respective control groups; (ii) an account of combined, L1- and/or L2-predominant influence in L3 production at the advanced level; and (iii) a comparison to background-language influence in L3 production at the intermediate level. To conclude, we provide some recommendations for future studies based on some of the limitations observed.

Regarding the native language, both experimental groups departed from monolingual values in their L1, which indicates that learning an L2 (at least at advanced levels) has had an impact on their pronunciation of L1 voiceless stops. This impact is more pronounced for Group TF, since the VOT means in their L1 and standard deviations show that part of their productions are likely to fall outside the $0-30 \mathrm{~ms}$ range suggested for French voiceless stops. In contrast, Group TA's means are significantly lower than those of English monolinguals, but their productions are more likely to stay within the 60-100 ms range suggested for English voiceless stops.

Moreover, none of the participants behaved like monolinguals in their L2 which, at first glance, corroborates the claim that it is hard to fully master VOT duration in a non-native language, as has been reported in the literature (e.g., Caramazza et al. 1973; Díaz-Campos 2004; however, 
see Birdsong 2007, for a counterexample). Nonetheless, the trilingual Francophones pattern with the trilingual Anglophones in English (they behave alike and significantly different from monolingual Anglophones). This finding (not too surprising, considering that participants from both groups live in an English-dominant context) means that both experimental groups have similar chances of producing English-accented (French and Spanish) voiceless stops. Recall that VOT has been linked to foreign accent in the Spanish of English speakers (Lord 2005). However, in their L3 Spanish, the Francophone Group approximates monolingual-like values more than the Anglophone Group especially for $/ \mathrm{p} /$ and / $t$ /, which could indicate minimal influence from the L2 on the L3, if any.

The main finding regarding L3 pronunciation was the underlying presence of L1 traits in both the L2 and the L3 of our participants. In the case of the Anglophone Group, this meant not being able to consistently produce short-lagged voiceless stops in the two non-native languages. Of note, however, Anglophones were able to further reduce the VOT values in their L3 in relation to their L2 French, which we have interpreted as a sign of partial acquisition of the L3 patterns. In the case of the Francophone Group, this meant being able to outperform Anglophones in Spanish. As shown by the intragroup analysis, their Spanish values were significantly reduced if compared to their L1 French. In our opinion, this points to the acquisition of L3 VOT values, rather than to positive transfer from the $\mathrm{L} 1$ alone.

As already discussed, Llama et al. (2010) claimed a predominant L2-to-L3 transfer pattern, since mean VOTs were relatively similar between the non-native languages across groups. In our current results, however, the L2 plays a less determinant role, especially in the case of Group TF. We had anticipated a potential reason for why our results could fail to replicate those from 2010: the increase in L3 proficiency. Our findings, together with Llama et al. (2010), appear to provide support to the claim that there is an L2 effect that weakens when the L3 is acquired and/or fades in favor of the L1 as proficiency increases (Hammarberg and Hammarberg 1993; Williams and Hammarberg 1998). Although we cannot report a clear switch to the L1 as a source language at a more advanced level, we have seen how Francophones in the current study were able to better overcome L2 influence ${ }^{7}$ to possibly benefit more from positive L1 transfer to the L3. Admittedly, acquisition of the L3 and L1-prevalent influence are hard to disentangle for Group TF. In this regard, it would have not been reasonable for Anglophones to switch to the L1, since relying on their L2 French is more advantageous, but it appears as if an underlying L1 effect were preventing them from fully attaining (French and) Spanish-like values.

In accounting for the differences between the two studies, it is worth adding that, for the most part, participants from the previous study were recruited at Montreal CEGEPs (Collèges d'enseignement général et professionnel, 'General and Vocational Colleges' in English) and universities, had never travelled to Spanish-speaking countries, and did not seem to associate with Hispanophones as part of their social lives. In the current study, in contrast, participants were older, most of them had been to Spanish-speaking countries, participated in Spanish conversation clubs in which native speakers also took part, and/or had regular contact with native or fluent Spanish speakers. We believe that real, meaningful exposure to Spanish has contributed to a higher achievement in the production of Spanish voiceless stops. Language exposure can also provide a plausible explanation as to why both the Anglophone and Francophone participants approximate Spanish VOT values more than French ones. English and French are in constant contact in the Ottawa-Gatineau region (in the Ontario-Quebec border in Canada), and it is reasonable to assume that our informants are exposed to somewhat accented English and, crucially, French on a regular basis.

7 Trilingual Francophones in the 2010 study produced L3 VOT means of $34 \mathrm{~ms}$ for $/ \mathrm{p} /, 33 \mathrm{~ms}$ for $/ \mathrm{t} /$, and $59 \mathrm{~ms}$ for $/ \mathrm{k} /$, which are considerably higher than the means we are reporting here. 


\section{Concluding Remarks}

Overall, it could be argued this study's main contribution to the subfield of L3 phonetics and phonology has been to examine the production of L3 VOT at advanced proficiency levels (cf. Llama et al. 2010, which focused on pre-advanced proficiency levels). Whereas the two related studies employed a cross-sectional approach, which allowed to portray static performance by two groups of Anglophones and two groups of Francophones at two different proficiency levels, a future study could benefit from a longitudinal design to better capture the dynamic nature of multilingual language learning, the different stages that characterize the phenomenon, and the potential switch in main source language for L3 production due to gains in proficiency.

It must be noted that the results at our disposal are limited to voiceless stops, which provide only a partial insight into the development of VOT patterns in L3 acquisition. Although it is common in this kind of research to target one set of stops, or one voiced-voiceless stop dyad, the inclusion of voiced stops, less frequently studied, would have been pertinent, as pointed out by an anonymous reviewer. On this note, we could remark that the three languages under investigation are similar in that they distinguish between two categories of stops (i.e., voiceless and voiced), but different with regard to how they differentiate the voiceless category: While voiceless stops can be aspirated or unaspirated in English (depending on segmental and prosodic factors; e.g., Nespor and Vogel 1986), the same stops can only be unaspirated in French and Spanish. Interestingly, if aspirated stops are incorrectly "unaspirated" in English, they are often perceived as voiced stops; this behavior assigns a phonemic status to this phonetic feature in English, similar to the voiced versus voiceless contrast in French and Spanish. For details on what these voiced/voiceless and aspirated/unaspirated differences entail, see Figure 1 and the related discussion on divergent lag patterns in Section 2. Accordingly, future studies should investigate both voiced and voiceless plosives to widen the scope of inquiry and thus offer a more comprehensive account of this issue. In this sense, another clear limitation of the present study is its small sample size. Not having larger groups as well as more comprehensive (and consequently longer) instruments has prevented us from carrying out a more thorough statistical analysis, which could have included relevant variables such as word length and following vowel.

While it was not our intention to focus on regressive transfer, we have found evidence of the impact of learning an L2 on the L1. This holds not only for learners immersed in an L2 setting (the case of our Group TF), as could be expected, but also for speakers who live in their L1 environment (such as our Group TA), although to a lesser extent. Undoubtedly, Ottawa can offer a favorable context for regressive transfer to take place. However, since this finding has also been reported in studies on bilinguals (Waniek-Klimczak 2011) learning an L2 (English) in an L1 setting (Poland), and on (Polish) trilinguals living in their L2 environment (Denmark; Sypiańska 2016), it may merit further investigation. Moreover, only a few L3 studies have considered regressive transfer from the L3, and at least three of them indicate a greater impact of the L3 on a native-like L2 sound system than on L1 speech production (Cabrelli Amaro and Rothman 2010; Cabrelli Amaro 2017; Liu 2016). This observation led to the proposal of the Phonological Permeability Hypothesis (Cabrelli Amaro and Rothman 2010; Cabrelli Amaro 2017), according to which "a late-acquired L2 is more vulnerable to L3 influence than an L1" (Cabrelli Amaro and Wrembel 2016, p. 403). Our study does not allow us to make claims in this regard, but we recognize that the topic deserves further attention in this (still) emergent field of L3 phonology.

Author Contributions: W.C. and R.L. prepared the instruments and conceived the experimental design; R.L. collected and analyzed the data; R.L. and W.C. wrote the paper.

Funding: This research received no external funding.

Acknowledgments: We thank Laura Colantoni for her suggestions and encouragement at the early stages of this project, as well as Laura Collins, two anonymous reviewers, and the editors of this special issue for their insightful comments on an earlier version of this paper. Our gratitude also goes to Laura Sánchez for her assistance with the statistical analyses. All remaining errors are our own.

Conflicts of Interest: The authors declare no conflict of interest. 


\section{Appendix A}

\section{Word Lists in Alphabetical Order}

Spanish list: cama, casa, codo, copa, cubo, cura, pala, pato, pelo, pena, piña, piso, poco, pollo, puño, puro, queja, queso, quinto, quita, talla, tarro, tela, tema, tina, tiro, toro, torre, tubo, tuyo.

French list: cadre, canne, coq, corde, cou, coût, pas, patte, pêche, père, pile, pipe, poche, pomme, poudre, pour, quelle, quête, quitte, tache, tasse, terre, tête, thon, tique, tir, tort, touche, tout.

English list: cabbage, cocky, cookie, cooler, copper, cuddle, kennel, kettle, killer, kitten, parrot, penny, pepper, pillow, pity, pocket, polish, poodle, pool, puppy, tacky, teller, tenant, tickle, tipping, toddler, toonie, tooth, topping, tummy.

\section{References}

Aoki, Rika, and Fumiaki Nishihara. 2013. Sound feature interference between two second languages: An expansion of the feature hypothesis to the multilingual situation in SLA. In Proceedings of the 37th Annual Meeting of the Berkeley Linguistics Society. Edited by Chundra Cathcart, I.-Hsuan Chen, Greg Finley, Shinae Kang, Clare S. Sandy and Elise Stickles. Berkeley: eScholarship: University of California, pp. 18-32.

Avery, Peter, and Susan Ehrlich. 1995. Teaching American English Pronunciation. Oxford: Oxford University Press. Bandeira, Marta Helena Tessmann, and Márcia Cristina Zimmer. 2012. The dynamics of interlanguage transfer of VOT patterns in multilingual children. Linguagem and Ensino 15: 341-64.

Bardel, Camilla, and Ylva Falk. 2007. The role of the second language in third language acquisition: The case of Germanic syntax. Second Language Research 23: 459-84. [CrossRef]

Beckmann, Eltje. 2012. A gup of dea, please: Crosslinguistic influence in English and German word-initial stops produced by German L3 learners of Dutch. Dutch Journal of Applied Linguistics 1: 252-62. [CrossRef]

Benrabah, Mohamed. 1991. Learning English segments with two languages. In Actes du XIIème Congrès International des Sciences Phonétiques. Aix-en-Provence: Université de Provence, Service des Publications, pp. 334-37.

Birdsong, David. 2007. Nativelike pronunciation among late learners. In Language Experience in Second Language Learning: In Honor of James Emil Flege. Edited by Ocke-Schwen Bohn and Murray J. Munro. Amsterdam: Benjamins, pp. 99-116.

Blank, Cintia Avila, and Márcia Cristina Zimmer. 2009. A transferência fonético-fonológica L2 (francês)-L3 (inglês): Um estudo de caso. Revista de Estudos da Linguagem 17: 207-33. [CrossRef]

Boersma, Paul, and David Weenink. 2014. Praat, A System for Doing Phonetics by Computer, Version 5.3.78. Available online: http:/ / www.praat.org (accessed on 14 December 2014).

Cabrelli Amarom, Jennifer. 2012. L3 phonology: An understudied domain. In Third Language Acquisition in Adulthood. Edited by Jennifer Cabrelli Amaro, Suzanne Flynn and Jason Rothman. Amsterdam and Philadelphia: John Benjamins, pp. 33-60.

Cabrelli Amaro, Jennifer. 2017. Testing the Phonological Permeability Hypothesis: L3 phonological effects on L1 versus L2 systems. International Journal of Bilingualism 21: 698-717. [CrossRef]

Cabrelli Amaro, Jennifer, and Jason Rothman. 2010. On L3 acquisition and phonological permeability: A new test case for debates on the mental representation of non-native phonological systems. International Review of Applied Linguistics in Language Teaching 48: 275-96.

Cabrelli Amaro, Jennifer, and Magdalena Wrembel. 2016. Investigating the acquisition of phonology in a third language-A state of the science and an outlook for the future. The International Journal of Multilingualism 13: 395-409. [CrossRef]

Caramazza, Alfonso, Grace H. Yeni-Komshiam, Edgar B. Zurif, and Emilio Carbone. 1973. The acquisition of a new phonological contrast: The case of stop consonants in French-English bilinguals. The Journal of the Acoustical Society of America 54: 421-28. [CrossRef] [PubMed]

Cho, Taehong, and Peter Ladefoged. 1999. Variation and universals in VOT: Evidence from 18 languages. Journal of Phonetics 27: 207-27. [CrossRef]

De Angelis, Gessica. 2007. Third or Additional Language Acquisition. Clevendon: Multilingual Matters. 
Díaz-Campos, Manuel. 2004. Context of learning in the acquisition of Spanish second language phonology. Studies in Second Language Acquisition 26: 249-73. [CrossRef]

Dittmers, Tetyana, Christoph Gabriel, Marion Krause, and Sveda Topal. 2018. The production of voiceless stops in multilingual learners of English, French, and Russian: Positive transfer from the heritage languages? In Proceedings of the 13th Conference on Phonetics and Phonology in the German-Speaking Countries. Edited by Malte Belz, Christine Mooshammer, Susanne Fuchs, Stefanie Jannedy, Oksana Rasskazova and Marzena Zygis. Berlin: ZAS, pp. 41-44.

Fellbaum, Marie L. 1996. The acquisition of voiceless stops in the interlanguage of second language learners of English and Spanish. In Proceedings of the 4th International Conference on Speech and Language Processing. Edited by H. Tim Bunnel and William Idsardi. Wilmington: Applied Science and Engineering Laboratories, pp. 1648-51.

Flege, James E. 1987. The production of new and similar phones in a foreign language: Evidence for the effect of equivalence classification. Journal of Phonetics 15: 47-65.

Flege, James E. 1991. Age of learning affects the authenticity of voice-onset time (VOT) in stop consonants produced in a second language. Journal of the Acoustical Society of America 89: 395-411. [CrossRef] [PubMed]

Flege, James E., and Wieke Eefting. 1987. Production and perception of English stops by native Spanish speakers. Journal of Phonetics 15: 67-83.

Fowler, Carol A., Valery Sramko, David J. Ostry, Sarah A. Rowland, and Pierre Hallé. 2008. Cross language phonetic influences on the speech of French-English bilinguals. Journal of Phonetics 36: 649-63. [CrossRef] [PubMed]

Gabriel, Christoph, Tanja Kupisch, and Jeanette Seoudy. 2016. VOT in French as a foreign language: A production and perception study with mono- and multilingual learners (German/Mandarin-Chinese). In Actes du $5^{e}$ Congrès Mondial de Linguistique Française. Edited by Franck Neveu, Gabriel Bergounioux, Marie-Hélène Côté, Jean-Michel Fournier, Sylvester Osu, Philippe Planchon, Linda Hriba and Sophie Prévost. Paris: ILP/EDP Sciences, pp. 1-14.

García Lecumberri, María Luisa, and Francisco Gallardo del Puerto. 2003. English EFL sounds in learners of different ages. In Age and the Acquisition of English as a Foreign Language. Edited by María del Pilar García-Mayo and María Luisa García Lecumberri. Clevendon: Multilingual Matters, pp. 115-35.

García-Mayo, María del Pilar. 2012. Cognitive approaches to L3 acquisition. International Journal of English Studies 12: 1-20. [CrossRef]

Gurski, Claire. 2006. The hybrid system of voice onset time in French/English bilinguals. The Journal of the Acoustical Society of America 119: 3392. [CrossRef]

Gut, Ulrike. 2009. Non-Native Speech: A Corpus-Based Analysis of Phonological and Phonetic Properties of L2 English and German. Frankfurt am Main: Peter Lang.

Gut, Ulrike. 2010. Cross-linguistic influence in L3 phonological acquisition. The International Journal of Multilingualism 7: 19-38. [CrossRef]

Hammarberg, Björn. 2009. Processes in Third Language Acquisition. Edinburgh: Edinburgh University Press.

Hammarberg, Björn. 2010. The languages of the multilingual: Some conceptual and terminological issues. International Review of Applied Linguistics 48: 91-104. [CrossRef]

Hammarberg, Björn, and Britta Hammarberg. 1993. Articulatory re-setting in the acquisition of new languages: Reports from the Department of Phonetics, University of Umea. Phonum 2: 61-67.

Hansen Edwards, Jette G., and Mary L. Zampini, eds. 2008. Phonology and Second Language Acquisition. Amsterdam: John Benjamins.

Jarvis, Scott, and Aneta Pavlenko. 2008. Crosslinguistic Influence in Language and Cognition. New York: Routledge.

Kamiyama, Takeki. 2007. Acquisition of French vowels by Japanese-speaking learners: Close and close-mid rounded vowels. Paper presented at the Satellite Workshop of ICPhS XVI, Freiburg, Germany, August 3-4.

Kissling, Elizabeth M. 2013. Teaching pronunciation: Is explicit phonetics instruction beneficial for FL learners? The Modern Language Journal 97: 720-44. [CrossRef]

Kopečková, Romana. 2015. Differences in the perception of English vowel sounds by child L2 and L3 learners. In Universal or Diverse Paths to English Phonology? Edited by Ulrike Gut, Robert Fuchs and Eva-Maria Wunder. Berlin: Mouton de Gruyter, pp. 71-90. 
Laeufer, Christiane. 1996. The acquisition of a complex phonological contrast: Voice timing patterns of English initial stops by native French speakers. Phonetica 53: 86-110. [CrossRef]

Lechner, Simone, and Martin Kohlberger. 2014. Phonetic transfer onto L3 English in subtractive bilinguals. Paper presented at the SLE 2014 Workshop on Advances in the Investigation of L3 Phonological Acquisition, Poznan, Poland, September 12.

Lisker, Leigh, and Arthur S. Abramson. 1964. A cross-language study of voicing in initial stops: Acoustical measurements. Word 20: 384-422. [CrossRef]

Liu, Zhao. 2016. Exploring Cross-Linguistic Influence: Perception and Production of L1, L2 and L3 of Bilabial Stops by Mandarin Chinese Speakers. Master's thesis, Universitat Autònoma de Barcelona, Barcelona, Spain.

Llama, Raquel, and Luz Patricia López-Morelos. 2016. VOT production by Spanish heritage speakers in a trilingual context. International Journal of Multilingualism 13: 444-58. [CrossRef]

Llama, Raquel, Walcir Cardoso, and Laura Collins. 2010. The influence of language distance and language status on the acquisition of L3 phonology. International Journal of Multilingualism 7: 39-57. [CrossRef]

Llisterri, Joaquim, and Dolors Poch. 1987. Les réalisations sonores dans l'apprentisage d'une troisième langue par bilingues. Revue de Phonétique Appliquée 82-83-84: 209-19.

Lord, Gillian. 2005. (How) can be teach foreign language pronunciation? On the effects of a Spanish Phonetics Course. Hispania 88: 557-67. [CrossRef]

MacLeod, Andrea A. N., and Carol Stoel-Gammon. 2009. The use of voice onset time by early bilinguals to distinguish homorganic stops in Canadian English and Canadian French. Applied Psycholinguistics 30: 53-77. [CrossRef]

Major, Roy Coleman. 2001. Foreign Accent: The Ontogeny and Phylogeny of Second Language Phonology. Mahwah: Lawrence Erlbaum Associates.

Mehlhorn, Grit. 2007. From Russian to Polish: Positive transfer in third language acquisition. Paper presented at 16th International Congress of Phonetic Sciences, Saarbücken, Germany, August 6-10; Edited by William J. Barry and Jürgen Trouvain. Saarbrücken: Universität des Saarlandes, pp. 1745-48.

Missaglia, Federica. 2010. The acquisition of L3 English vowels by infant German-Italian bilinguals. International Journal of Multilingualism 7: 58-74. [CrossRef]

Nespor, Marina, and Irene Vogel. 1986. Prosodic Phonology. Dordrecht: Foris.

Pyun, Kwang-soo. 2005. A model of interlanguage analysis-The case of Swedish by Korean speakers. In Introductory Readings in L3. Edited by B. Hufeisen and R. Fouser. Tübingen: Staufenberg Verlag, pp. 55-70.

Riney, Timothy J., and Naoyuki Takagi. 1999. Global foreign accent and voice onset time among Japanese EFL speakers. Language Learning 49: 275-302. [CrossRef]

Sánchez, Laura. 2011. "Luisa and Pedrito's dog will the breakfast eat": Interlanguage transfer and the role of the second language factor. In New Trends in Crosslinguistic Influence and Multilingualism Research. Edited by Gessica de Angelis and Jean-Marc Dewaele. Clevendon: Multilingual Matters, pp. 86-104.

Suarez, Philip. 2008. The pronunciation of the aspirated consonants $\mathrm{p}, \mathrm{t}$, and $\mathrm{k}$ in English by native speakers of Spanish and French. In Proceedings of the Seventh Annual College of Education Research Conference: Urban and International Education Section. Edited by Maria S. Plakhotnik and Sarah M. Nielsen. Miami: Florida International University, pp. 144-50.

Sundara, Megha, Linda Polka, and Shari Baum. 2006. Production of coronal stops by simultaneous bilingual adults. Bilingualism: Language and Cognition 9: 97-114. [CrossRef]

Sypiańska, Jolanta. 2013. Quantity and Quality of Language of Language Use and L1 Attrition of Polish due to L2 Danish and L3 English: The Role of L2 Proficiency. Ph.D. dissertation, Adam Mickiewicz University, Poznan, Poland.

Sypiańska, Jolanta. 2016. Multilingual acquisition of vowels in L1 Polish, L2 Danish, and L3 English. International Journal of Multilingualism 13: 476-95. [CrossRef]

Tremblay, Marie-Claude. 2007. L2 influence on L3 pronunciation: Native-like VOT in the L3 Japanese of English-French bilinguals. Paper presented at the Satellite Workshop of ICPhS XVI, Freiburg, Germany, August 3-4.

Waniek-Klimczak, Ewa. 2011. Aspiration and style: A sociophonetic study of the VOT in Polish learners of English. In Achievements and Perspectives in SLA of Speech. Edited by Magdalena Wrembel, Małgorzata Kul and Katarzyna Dziubalska-Kolaczyk. Frankfurt: Peter Lang, pp. 303-16. 
Williams, Sarah, and Bjorn Hammarberg. 1998. Language switches in L3 production: Implications for a polyglot speaking model. Applied Linguistics 19: 295-333. [CrossRef]

Wrembel, Magdalena. 2010. L2-accented speech in L3 production. International Journal of Multilingualism 7: 75-90. [CrossRef]

Wrembel, Magdalena. 2011. Crosslinguistic influence in third language acquisition of voice onset time. Paper presented at 17th International Congress of Phonetic Sciences, Hong Kong, China, August 17-21; Edited by Lee Wai-Sum and Eric Zee. Hong Kong: City University of Hong Kong, pp. 2157-60.

Wrembel, Magdalena. 2014. VOT patterns in the acquisition of Third Language Phonology. Concordia Papers in Applied Linguistics 5: 751-71.

Wrembel, Magdalena. 2015. In Search of a New Perspective: Cross-Linguistic Influence in the Acquisition of Third Language Phonology. Poznan: Wydawnictwo Naukowe UAM.

Wunder, Eva-Maria. 2011. Cross-linguistic Influence in Multilingual Language Acquisition: Phonology in Third or Additional Language Acquisition. In New Trends in Crosslinguistic Influence and Multilingualism Research. Edited by Gessica de Angelis and Jean-Marc Dewaele. Clevendon: Multilingual Matters, pp. 105-28.

Yavaş, Mehmet, and Renée Wildermuth. 2006. The effects of place of articulation and vowel height in the acquisition of English aspirated stops by Spanish speakers. International Review of Applied Linguistics 44: 251-63. [CrossRef]

(C) 2018 by the authors. Licensee MDPI, Basel, Switzerland. This article is an open access article distributed under the terms and conditions of the Creative Commons Attribution (CC BY) license (http://creativecommons.org/licenses/by/4.0/). 